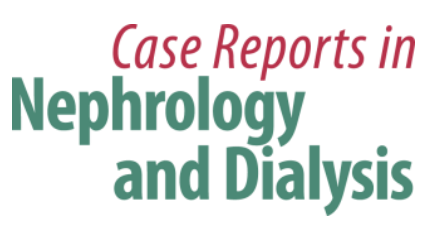

\title{
Reversible Ceftriaxone-Induced Pseudolithiasis in an Adult Patient with Maintenance Hemodialysis
}

\author{
Aya Shima $^{a}$ Takaichi Suehiro $^{a}$ Misaki Takii $^{a}$ Hiroyasu Soeda $^{b}$ \\ Makoto Hirakawa ${ }^{a}$ \\ Departments of ${ }^{a}$ Nephrology and ${ }^{b}$ Radiology, Harasanshin Hospital, Fukuoka, Japan
}

\section{Key Words}

Ceftriaxone $\cdot$ Pseudolithiasis · Adult $\cdot$ Maintenance hemodialysis

\begin{abstract}
Ceftriaxone (CTRX) is a third-generation cephalosporin widely used for the treatment of bacterial infections in patients with renal disease because of its excretion by both renal and hepatic mechanisms. Biliary pseudolithiasis is a known CTRX-associated complication; however, there have been no studies of this adverse event in adult patients receiving maintenance hemodialysis. Here we report the case of a 79-year-old Japanese woman with end-stage renal disease (ESRD) receiving maintenance hemodialysis who developed CTRX-induced pseudolithiasis. The patient received CTRX for bronchial pneumonia. Fifteen days following CTRX initiation, the patient presented with stomachache. Because of the presence of one gallstone and increased gallbladder wall thickness on computed tomography scans, not detected at the onset of pneumonia, the patient was diagnosed with CTRX-induced gallbladder pseudolithiasis. CTRX was discontinued immediately. At 48 days following CTRX withdrawal, the gallstone and thickening of the gallbladder wall had completely resolved. ESRD may be a risk factor for CTRX-induced pseudolithiasis as hepatic excretion of CTRX is the predominant clearance mechanism in patients with ESRD. More attention should be paid to CTRX-induced pseudolithiasis following the use of CTRX in ESRD patients.

(c) 2015 S. Karger AG, Basel
\end{abstract}

\section{Introduction}

Ceftriaxone (CTRX) is a broad-spectrum third-generation cephalosporin antibiotic with favorable tissue absorption. Because of its long half-time in plasma and metabolism via both

KARGER 125/s $\quad \begin{aligned} & \text { Aya Shima, MD } \\ & \text { Department of Nephrology } \\ & \text { Harasanshin Hospital } \\ & 1-8 \text { Taihakumachi, Hakata-ku, Fukuoka 812-0033 (Japan) } \\ & \text { E-Mail ayatakashima.adv@gmail.com }\end{aligned}$




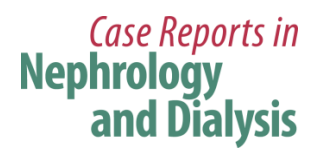

Case Rep Nephrol Dial 2015;5:187-191

DOI: $10.1159 / 00044068$

Shima et al.: Reversible Ceftriaxone-Induced Pseudolithiasis in an Adult Patient with Maintenance Hemodialysis

renal and hepatic excretion, CTRX is widely used to treat bacterial infectious diseases not only in patients without any underlying disease, but also in patients with renal disease $[1,2]$. Biliary pseudolithiasis is a known CTRX-associated adverse event $[3,4]$. It has been proposed that high doses of CTRX are excreted into the bile, where excreted CTRX then binds with calcium. The CTRX-calcium complexes then precipitate as biliary pseudolithiasis, and these stones may finally lead to the development of CTRX-induced pseudolithiasis [5]. Reported risk factors for CTRX-induced pseudolithiasis include pediatric age, high-dose or long-term CTRX treatment, hypercalcemia, fasting, total parenteral nutrition, renal failure, and previous history of major surgery [5-9]. However, there have been no reports regarding CTRX-induced pseudolithiasis in adult patients receiving maintenance hemodialysis. Here we describe a case of CTRX-induced pseudolithiasis in an adult patient receiving maintenance hemodialysis that resolved following CTRX cessation.

\section{Case Report}

A 79-year-old Japanese woman (height, $135.0 \mathrm{~cm}$; weight, $29.9 \mathrm{~kg}$ ) having received maintenance hemodialysis for 6 years due to end-stage renal disease (ESRD) as a result of antineutrophil cytoplasmic antibody-associated glomerulonephritis was referred to our hospital because of a fever of $37.7^{\circ} \mathrm{C}$, cough, and general fatigue. A blood analysis at presentation revealed a white blood cell (WBC) count of $6,500 / \mu \mathrm{l}$ and a C-reactive protein (CRP) level of $10.8 \mathrm{mg} / \mathrm{dl}$ with hepatic and biliary enzymes within normal limits. Inflammatory infiltrates were detected in the middle and right lower lung fields by plain chest radiography. Computed tomography (CT) scans revealed ground-glass opacification throughout the middle and right lower lung fields. The patient was normoxic. She was diagnosed with bronchial pneumonia, and $1 \mathrm{~g}$ of CTRX on alternating days was initiated intravenously following hemodialysis in consideration of its nondialyzability.

The cough, fever, general fatigue, and laboratory data steadily improved following CTRX administration. The WBC count was 5,300/ $\mu$ land the CRP level was $1.4 \mathrm{mg} / \mathrm{dl}$ on the 11 th day after CTRX initiation. However, on the 13th day, she unexpectedly presented with stomachache around the right hypochondrium with a firm, round mass and a slight fever of $37.2^{\circ} \mathrm{C}$. The WBC count was $10,560 / \mu \mathrm{l}$, the CRP level was $8.8 \mathrm{mg} / \mathrm{dl}$, and hepatic and biliary enzymes were within normal limits. To determine the source of her stomachache and slight fever, immediate imaging studies were performed. CT scans revealed improvement of her pneumonia; however, one gallstone $(16 \times 9 \mathrm{~mm})$ was revealed in the gallbladder with thickening of the gallbladder wall that was not detected on the previous CTs (fig. 1a, b). Therefore, CTRX-induced gallbladder pseudolithiasis was suspected, and CTRX was immediately discontinued. The total dose of CTRX administered was $7 \mathrm{~g}$ over 13 days. Although her stomachache had completely resolved 4 days after CTRX cessation, follow-up CTs demonstrated no significant change in the gallstone or gallbladder wall thickness at day 5 following CTRX cessation. Twelve days following CTRX withdrawal, the gallstone and increased gallbladder wall thickness gradually improved. Finally, the gallstone completely disappeared 48 days following CTRX cessation (fig. 1c). The patient survived disease free for 5 months after disappearance of the gallstone without any symptoms of cholelithiasis or cholecystitis. 


\section{Case Reports in \\ Nephrology \\ and Dialysis}

\begin{tabular}{l|l}
\hline \multicolumn{2}{l}{ Case Rep Nephrol Dial 2015;5:187-191 } \\
\hline DOI: 10.1159/000440680 & $\begin{array}{l}\text { ○ 2015 S. Karger AG, Basel } \\
\text { www.karger.com/cnd }\end{array}$ \\
\hline
\end{tabular}

Shima et al.: Reversible Ceftriaxone-Induced Pseudolithiasis in an Adult Patient with Maintenance Hemodialysis

\section{Discussion}

CTRX is a widely used broad-spectrum third-generation cephalosporin antibiotic. CTRX is cleared by both renal and hepatic excretion, meaning that CTRX has become a standard option in patients with renal disease, including hemodialytic patients $[1,2,10]$. In general, CTRX is relatively safe and effective; however, it occasionally causes adverse events. Biliary pseudolithiasis is one of the CTRX-associated adverse events $[3,4]$. To the best of our knowledge, this is the first report of CTRX-induced pseudolithiasis in an adult patient receiving maintenance hemodialysis.

The first report of CTRX-induced biliary pseudolithiasis was in a population of pediatric patients [11]. Since then, there have been many reports of CTRX-induced pseudolithiasis, although these reports have mainly been on pediatric patients and rarely on adults [9]. By utilizing ultrasound examinations, Heim-Duthoy et al. [12] revealed that the incidence of CTRX-induced pseudolithiasis in adult patients is approximately $20 \%$; however, only $30 \%$ of these $20 \%$ presented with clinical symptoms. These reports indicate that physicians are unable to detect asymptomatic CTRX-induced pseudolithiasis; nevertheless, this is rarely a clinical issue, since most cases of symptomatic and asymptomatic pseudolithiasis in these patients resolve spontaneously following CTRX withdrawal. There have been many other reports suggesting that CTRX-induced pseudolithiasis is reversible with discontinuation of CTRX [9]. Abnormal gallbladder sonograms were found 3-22 days (mean, 9 days) following CTRX initiation. The period between abnormal sonograms and returning to normal was 263 days (mean, 15 days) from CTRX cessation [3]. Thus, CTRX-induced pseudolithiasis is not very rare; however, there have been few reports regarding CTRX-induced pseudolithiasis in adult patients. This is particularly true for patients with ESRD, as there is only one report of an adult peritoneal dialysis patient [10].

It has been proposed that the formation of a CTRX-calcium complex is key to the development of biliary pseudolithiasis. Although approximately $30-70 \%$ of CTRX is eliminated unchanged via renal excretion, the remainder is excreted into bile. CTRX in bile exists as a divalent anion. The concentration of CTRX in the gallbladder can reach levels 20-150 times higher than in serum. These high concentrations of CTRX may bind with calcium cations in bile, similar to bilirubin. CTRX-calcium complexes may then precipitate. Afterward, the precipitated sludge forms stones and may finally develop into CTRX-induced pseudolithiasis [5]. On the basis of these mechanisms, proposed risk factors of CTRX-induced pseudolithiasis include: (1) hypercalcemia, which increases calcium secretion in the bile; (2) fasting, dehydration, and total parenteral nutrition, decreasing bile flow; (3) pediatric age, renal failure, or high-dose and long-term treatment, increasing the proportion of CTRX excretion into bile, and (4) a previous history of major surgery, which may cause gallbladder stasis [5-9].

Biner et al. [7] prospectively analyzed 156 children treated with varying CTRX doses $(50,75$, and $100 \mathrm{mg} / \mathrm{kg} /$ day) and reported that independent risk factors for CTRX-induced biliary pseudolithiasis were age and higher CTRX dosages. The incidence of CTRX-induced biliary pseudolithiasis reached around 33\% in patients receiving $100 \mathrm{mg} / \mathrm{kg} /$ day of CTRX and $11 \%$ in patients receiving $50 \mathrm{mg} / \mathrm{kg} / \mathrm{day}$ [7]. On the other hand, our patient developed biliary pseudolithiasis despite receiving only $16 \mathrm{mg} / \mathrm{kg} /$ day of CTRX. The patient had been anuric for more than 4 years previously because of ESRD. Consequently, CTRX could not be metabolized or excreted by the kidney, but only by the liver. Additionally, CTRX is not dialyzable [13]. Therefore, even very small doses of CTRX were able to increase gallbladder concentrations, potentially leading to the development of CTRX-induced biliary pseudolithiasis. 


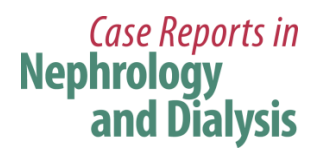

\begin{tabular}{l|l}
\hline \multicolumn{2}{l}{ Case Rep Nephrol Dial 2015;5:187-191 } \\
\hline DOI: 10.1159/000440680 & $\begin{array}{l}\text { ○ 2015 S. Karger AG, Basel } \\
\text { www.karger.com/cnd }\end{array}$ \\
\hline
\end{tabular}

Shima et al.: Reversible Ceftriaxone-Induced Pseudolithiasis in an Adult Patient with Maintenance Hemodialysis

As described above, liver-excreted CTRX binds with calcium in bile, and the formation of CTRX-calcium complexes may lead to CTRX-induced pseudolithiasis. Patients on maintenance hemodialysis occasionally receive alfacalcidol and a calcium-based phosphate binder to prevent secondary hyperparathyroidism, and these patients consequently tend to develop hypercalcemia [14]. In our case, the patient was being treated with $0.25 \mu \mathrm{g} /$ day of alfacalcidol, but not calcium carbonate or bisphosphonate. Her albumin-adjusted serum calcium levels on admission were approximately $9.5-9.9 \mathrm{mg} / \mathrm{dl}$, and the serum whole parathyroid hormone level was approximately $13-20 \mathrm{pg} / \mathrm{ml}$. The ability of vitamin D and whole parathyroid hormone to increase calcium secretion into bile is controversial; however, patients receiving hemodialysis, and especially those receiving vitamin D or calcium-based phosphate binders, may be at higher risk of CTRX-induced pseudolithiasis.

Furthermore, UDP glucuronosyltransferase 1A1 (UGT1A1) gene polymorphisms also have been proposed as a possible risk factor for CTRX-induced pseudolithiasis [15]. In our case, we did not check whether the patient possessed these gene polymorphisms; however, the evaluation of such a genetic risk before using CTRX would be very useful to protect patients from this adverse event. Further large-scale studies to confirm this genetic risk factor are warranted.

We described a case of CTRX-induced pseudolithiasis in an ESRD patient receiving maintenance hemodialysis. Hemodialytic patients may be at higher risk of CTRX-induced pseudolithiasis. More attention should be paid to CTRX-induced pseudolithiasis in hemodialytic patients.

\section{Acknowledgements}

We thank the medical and nursing staff working in Harasanshin Hospital and Dr. Yanase's internal medicine office.

\section{Disclosure Statement}

There is no conflict of interest in this paper.

\section{References}

$\checkmark 1$ Arvidsson A, Alvan G, Angelin B, Borga O, Nord CE: Ceftriaxone: renal and biliary excretion and effect on the colon microflora. J Antimicrob Chemother 1982;10:207-215.

2 Richards DM, Heel RC, Brogden RN, Speight TM, Avery GS: Ceftriaxone. A review of its antibacterial activity, pharmacological properties and therapeutic use. Drugs 1984;27:469-527.

-3 Schaad UB, Wedgwood-Krucko J, Tschaeppeler H: Reversible ceftriaxone-associated biliary pseudolithiasis in children. Lancet 1988;2:1411-1413.

4 Pigrau C, Pahissa A, Gropper S, Sureda D, Martinez Vazquez JM: Ceftriaxone-associated biliary pseudolithiasis in adults. Lancet 1989;2:165.

-5 Shiffman ML, Keith FB, Moore EW: Pathogenesis of ceftriaxone-associated biliary sludge. In vitro studies of calcium-ceftriaxone binding and solubility. Gastroenterology 1990;99:1772-1778.

-6 Lee SP, Lipsky BA, Teefey SA: Gallbladder sludge and antibiotics. Pediatr Infect Dis J 1990;9:422-423.

7 Biner B, Oner N, Celtik C, Bostancioğlu M, Tunçbilek N, Güzel A, Karasalihoğlu S: Ceftriaxone-associated biliary pseudolithiasis in children. J Clin Ultrasound 2006;34:217-222.

-8 Ettestad PJ, Campbell GL, Welbel SF, Genese CA, Spitalny KC, Marchetti CM, Dennis DT: Biliary complications in the treatment of unsubstantiated Lyme disease. J Infect Dis 1995;171:356-361.

-9 Bickford CL, Spencer AP: Biliary sludge and hyperbilirubinemia associated with ceftriaxone in an adult: case report and review of the literature. Pharmacotherapy 2005;25:1389-1395. 
Shima et al.: Reversible Ceftriaxone-Induced Pseudolithiasis in an Adult Patient with Maintenance Hemodialysis

-10 Rivera M, García-Herrera AL, Burguera V, Sosa-Barrios H, Palomares JR, Quereda C: Ceftriaxone-associated gallbladder pseudolithiasis in a PD patient. Perit Dial Int 2011;31:97-99.

11 Schaad UB, Tschäppeler H, Lentze MJ: Transient formation of precipitations in the gallbladder associated with ceftriaxone therapy. Pediatr Infect Dis 1986;5:708-710.

12 Heim-Duthoy KL, Caperton EM, Pollock R, Matzke GR, Enthoven D, Peterson PK: Apparent biliary pseudolithiasis during ceftriaxone therapy. Antimicrob Agents Chemother 1990;34:1146-1149.

$\checkmark 13$ Patel IH, Sugihara JG, Weinfeld RE, Wong EG, Siemsen AW, Berman SJ: Ceftriaxone pharmacokinetics in patients with various degrees of renal impairment. Antimicrob Agents Chemother 1984;25:438-442.

14 Shahapuni I, Mansour J, Harbouche L, Maouad B, Benyahia M, Rahmouni K, Oprisiu R, Bonne JF, Monge M, El Esper N, Presne C, Moriniere P, Choukroun G, Fournier A: How do calcimimetics fit into the management of parathyroid hormone, calcium, and phosphate disturbances in dialysis patients? Semin Dial 2005;18:226238.

15 Fretzayas A, Liapi O, Papadopoulou A, Nicolaidou P, Stamoulakatou A: Is ceftriaxone-induced biliary pseudolithiasis influenced by UDP-glucuronosyltransferase 1A1 gene polymorphisms? Case Rep Med 2011;2011:730250.
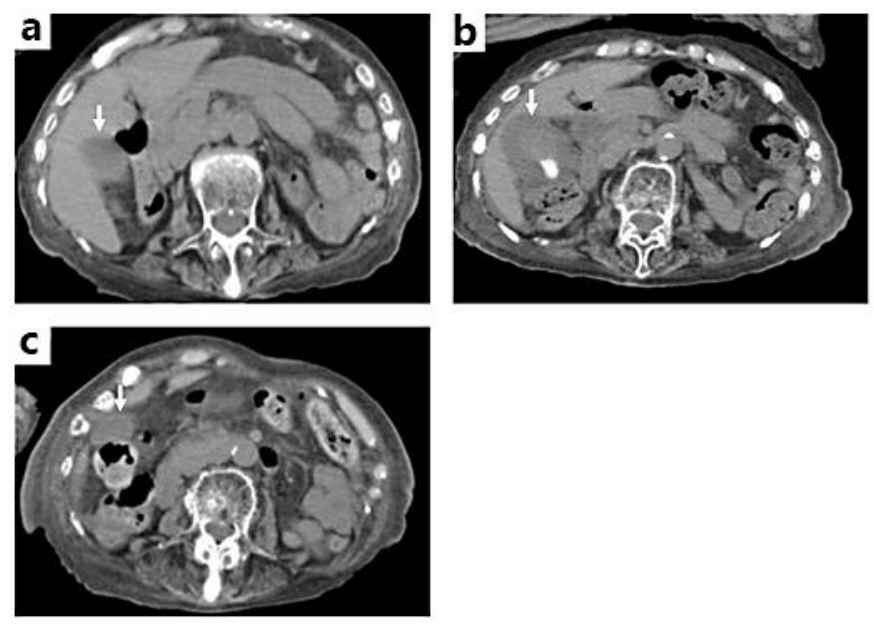

Fig. 1. Images from abdominal CT scanning. The white arrows indicate the gallbladder. a The gallbladder was normal in size, shape, and location, and no gallstone was detected just prior to CTRX administration. b A stone in the gallbladder and thickening of the gallbladder wall were detected 13 days following CTRX initiation. $\mathrm{c}$ The stone and thickened wall of the gallbladder resolved 48 days following CTRX cessation. 